\title{
Valuing ecosystem services of Sundarbans mangrove forest for improved conservation: approach of randomized conjoint experiment
}

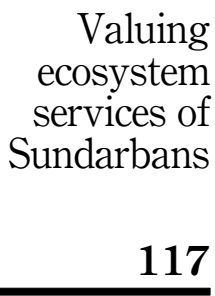

Received 30 April 2020 Revised 17 October 2020 Accepted 17 October 2020

\begin{abstract}
Purpose - This study provides empirical evidence of the economic valuation of ecosystem services. It examines the willingness-to-pay (WTP) and compensating surplus (CS) in response to policy change based on focus group discussion (FGD) and survey.

Design/methodology/approach - A randomized conjoint analysis based experiment was conducted in seven villages of Sundarbans in Bangladesh to elicit stated preference data and measure WTP and CS. Each respondent faced three options in every choice card-two hypothetical alternatives and one status quo scheme. Four alternatives - payment for ecosystem services, storm protection, erosion control and habitat for fish breeding - are randomly and simultaneously assigned to the two alternatives.

Findings - The findings suggest that age, income, education, family size and occupational status are the influential factor to choice the relevant attributes of ecosystem services and their levels. Villagers would like to pay annually Tk. 703, Tk. 281, and Tk. 59 for lower, moderate, and higher ecosystem services. With these WTP, they get surplus Tk. 760, Tk. 138, and Tk. 346 respectively.

Research limitations/implications - The lower WTP does not necessarily imply low demand for ecosystem service, as the findings from WTP illustrate potential demand for ecosystem services of Sundarbans.

Practical implications - The study provides an important insight into the ecosystem services and values of Sundarbans mangrove forests for welfare and can inform policy for sustainable use of resources of this forest. Originality/value - There is a crucial gap in understanding what could villagers be ready for WTP for better ecosystem services of Sundarbans mangrove forest, how do payment based ecosystem services, as a proxy for the conservation of Sundarbans mangrove, and to what extent the policy can be strengthened.
\end{abstract}

Keywords Conjoint analysis, Behavioral economics, Economic of forest, Willingness-to-pay,

Compensating surplus

Paper type Research paper

\section{Background}

Mangroves (Tidal forests) have substantial and economic importance at local, national and global perspectives. It has balanced the ecosystem-serving as fish nurseries, havens of biodiversity and carbon storehouses. Globally, mangrove forests act as extremely effective carbon sinks, being able to absorb 97.57 tons of carbon per hectare, or more than three times the absorptive capacity of non-mangroves forest (Austin, 2020). Mangrove forest ecosystem generates enormous benefits such as biological diversity, watershed protection and the sociocultural functions. It is works as an independent biome essential for rich biodiversity.

\section{JEL Classification - C31, Q23, Q51, Q56, Q57}

(C) Md. Hafiz Iqbal. Published in Forestry Economics Review. Published by Emerald Publishing Limited. This article is published under the Creative Commons Attribution (CC BY 4.0) licence. Anyone may reproduce, distribute, translate and create derivative works of this article (for both commercial and non-commercial purposes), subject to full attribution to the original publication and authors. The full terms of this licence may be seen at http://creativecommons.org/licences/by/4.0/legalcode

This research was not supported by grants from any organization. The author is indebted to the anonymous reviewers and the editor.

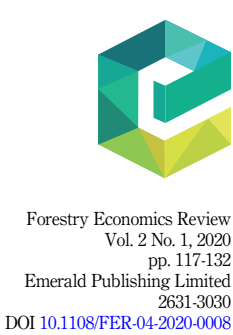


FER

2,1

118

Over 1,186 numbers of known living species (flora and fauna) are found in the biome (Rahman and Begum, 2011). It is the breeding ground for several globally threatened species, including the endangered Ganges river dolphin, the masked fine foot, the water bird, the Bengal tiger and other species of reptiles. It plays an important role in the reclamation of land, protection of coastal habitat from cyclones and tidal surges, and uplifts the socio-economic condition of the coastal people. It also contributes directly to well-being, livelihood, and cultural and supporting services (Uddin et al., 2013a; Shameem et al., 2014). Livelihood options and life support functions to people of this forest area depend on the Sundarbans ecosystem through fishing, collection of honey and fuel wood/timber (Ekka and Pandit, 2012). Most of these people are illiterate and poor, hence their dependence on mangrove is larger beyond our expectation (Hussain and Badola, 2010; Iqbal, 2020).

Qualitative narratives of biosphere-supporting contributors of Sundarbans are not counted by the market mechanism and often less persuasive in decision making than quantitative valuation (Daily et al., 1997). While translating the value of the ecosystem into further explicit monetary terms is highly advocated, it claims necessary knowledge of activities and preferences of community people and their socio-economic-cultural practice for decision making (Rahman et al., 2018). It also requires sound methodological ground which is effectively measured and the value of the ecosystem.

This forest is declared as protected area and world heritage site in 1997 by the International Union for Conservation of Nature (IUCN) and the United Nations Educational, Scientific and Cultural Organization (UNESCO) and hence, it gained immense popularity as a tourist destination for both domestic and international tourists (Protect Planet, 2018; UNESCO, 2018, Amin, 2018). But unbridled and native anthropogenic avarice is receiving a heavy toll of Sundarbans (Sen and Ghorai, 2019). The Sundarbans mangrove ecosystem is now in captious position and is declining at an alarming rate. It is causing extinction more rapidly than inland tropical forests. The forest themselves are dynamic and are undergoing constant changes due to both climatic and anthropogenic forces (Giri et al., 2008). More specifically, the decline in the region's mangrove forest can be attributed to a range of deforestation drivers due to climatic factors, morphological events, biological invasions and human behavior. As a consequence, it is difficult to survive for the Sundarbans mangrove ecosystem under adverse conditions.

Existing studies have documented the history, utilization, conservation strategies, causes of degradation and ecosystem services and dependent livelihoods, and sustainable management options of Sundarbans (Ghosh et al., 2015; Uddin et al., 2013b; Islam and Bhuiyan, 2018; Islam, 2014), but a very few studies have quantified ecosystem services of this forest and monetize their value (Rahman et al., 2018; Mukherjee et al., 2014; Gunawardena and Rowan, 2005). There is a crucial gap in understanding what could villagers be ready for WTP for better ecosystem services of Sundarbans mangrove forest, how do payment based ecosystem services, as a proxy for the conservation of Sundarbans mangrove, and to what extent the policy can be strengthened. This study explores the WTP for ecosystem services in Sundarbans and develops management strategy of this ecosystem services.

\section{Theoretical framework}

For figuring out the alternative benefits of ecosystem services, it requires some criteria of social well-being or welfare which needs some ethical standard and interpersonal comparisons for subjective value judgment. The utilitarian approach effectively assesses the ecosystem services (Muthukrishnan, 2015). This approach is a branch of moral philosophy associated with the English philosopher and economist Jeremy Bentham (17481832) and has a broader scope to apply ecosystem valuation. Bentham believed that wellbeing is improved in society when the desirable good or service secured by the greatest 
number. This implies that total well-being is the total of the utilities of individuals in any society. Under this proposition, every individual can desire or choose a particular ecosystem service from bundles of ecosystem services. The randomized conjoint analysis provides the best way to select desirable ecosystem services from a bundle of ecosystem services. This experimental approach was first developed by the idea of contact hypothesis (under appropriate conditions, interpersonal contact is one of the most effective ways to diminish prejudice) formulated by Gordon Allport, a professor of psychology at Harvard in 1954 (Banerjee and Duflo, 2019). The following section briefly explains the framework of the conjoint experiment approach.

\subsection{Conjoint experiment}

Nobel Laureate economist Vernon Smith is a predecessor of experimental economics. It is a very effective approach for quantitative analysis in the sense that it presents an individual's preferences and choices from a bundle of ecosystem services. It is a type of conjoint valuation technique elicits by tangent stated preference over different hypothetical alternatives and has significant advantages.

Individuals are traders. They consciously or sub-consciously make decisions by comparing alternative and selecting an action which is known as a choice outcome. This study will draw on ideas from economics and psychology perspective, starting with the notion that it is an individual's preference for specific alternatives that best determine what alternative is chosen.

The overall utility associated with the $i$ th alternative can be divided into the contributions that are observed by the researcher and those that are not observed by the researcher. Suppose these sources of relative utility represent as $V_{i}$ and. $V_{i}$ is the deterministic portion of the utility and $\epsilon$ is a common notation that is used to refer to the unobserved influences as error or random error term. In the conjoint analysis, both $V_{i}$ and $\varepsilon_{i}$ have great relevance. It is assumed that there is a strong relationship between $V_{i}$ and $\varepsilon_{i}$. These two components are independent and additive. A utility function is strongly additive if it can be written as follows:

$$
U=\sum_{i=1}^{n} f_{i}\left(q_{i}\right)
$$

where $f_{i}$ are increasing. Additive is a special case of separability. Any utility function that has a monotonic transformation which is additive may be treated as being additive for all theorems applicable to additive functions (Henderson and Quandt, 1980). An additive utility function has the property that all cross partials equal zero, i.e.

$$
\delta^{2} U / \delta q_{i} \delta q_{j}=0 \text { for all } i \neq j
$$

It will take the form under the strict quasi-concavity condition and the two-variable case as follows:

$$
f_{11} f_{2}^{2}+f_{22} f_{1}^{2}<0
$$

A behavioral choice rule can be perfectly explained by the random utility theory (RUT), Lancasterian theory of value, compensating surplus (CS), and willingness-to-pay (WTP).

2.1.1 Random utility theory (RUT). The concept of random utility theory (RUT) is very similar to the random service theory (RST) and plays an important role to explain consumer behavior. RUT says that not all of the determinants of utility derived by individuals from their choices are directly observable to the researcher, but that an indirect determinant of preferences is possible (McFadden, 1974; Manski, 1977). The utility function for a representative consumer can be decomposed into observable and stochastic sections: 
FER

2,1

120

$$
U_{a n}=V_{a n}+\varepsilon_{a n}
$$

where $U_{a n}$ is the latent and unobservable utility held by consumer $n$ for choice alternative $a$, $V_{a n}$ is the systemic or an observable portion of utility that consumer $n$ has for choice alternative $a$ and $\varepsilon_{a n}$ is the random or unobservable portion of the utility that consumer $n$ has for choice alternative $a$. Research is focused on a probability function, defined over the alternatives which an individual faces, assuming that the individual will try to maximize his utility (Bennett and Blamey, 2001; Louviere et al., 2000). This probability is expressed as follows:

$$
\left.P\left(a / C_{n}\right)=P\left[\left(V_{a n}+\varepsilon_{a n}\right)\right\rangle\left(V_{j n}+\varepsilon_{j n}\right)\right] \forall_{a} \neq j
$$

for all $j$ options in choice set $C_{n}, a$ and $n$ are also described as follows:

$$
P\left(a / C_{n}\right)=P\left[\left(V_{a n}-V_{j n}\right)>\left(\varepsilon_{j n}-\varepsilon_{a n}\right)\right] \forall_{a} \neq j
$$

Equation (6) holds the principle of RUT, which exhibits the stochastic components are independently and identically distributed (IID) with a Gumbel or Weibull distribution. This leads to the use of the conditional logit model. It helps to determine the probability of choosing $a$ over $j$ option (Hanley et al., 2001; Alpizar et al., 2001). The estimated deterministic (indirect) utility function generally will have the following form:

$$
P\left(U_{a n}>U_{j n}\right)=\frac{\exp \left(\mu V_{a}\right)}{\sum j \exp \left(\mu V_{j}\right)} \forall_{a} \neq j
$$

Here, $\mu$ is a scale parameter, inversely related to the standard deviation of the error term and not separately identified in a single data set (Bergmann $e t$ al., 2006). The $\beta$ values cannot be directly interpreted as to their contribution to utility, since using the MNL model choices must satisfy the independence from irrelevant alternatives (IIA) assumption, meaning that the addition or subtraction of any option from the choice set will not affect the relative probability of individual $n$ choosing any other option (Louviere et al., 2000; Bergmann et al., 2006). Modeling constants known as alternative specific constants (ASCs) are typically included in the basic logit model. The ASC accounts for variations in choices are not explained by the attributes or socio-economic-demographic (SED) variables and sometimes for a status quo bias (Ben-Akiva and Lerman, 1985).

The random parameter logit or extended model provides a simple way to generalize the multinomial logit model to permit the utilities of each alternative to be correlated and it does not require IIA assumption (Cameron and Trivedi, 2005). The random utility function in the random parameter logit model will take the following form (Birol et al., 2005).

$$
U_{\text {in }}=V_{\text {in }}+\varepsilon_{\text {in }} \equiv Z_{i}\left(\beta+\eta_{n}\right)+\varepsilon_{\text {in }}
$$

As we know utility is decomposed into a non-random component ( $V$ ) and a stochastic term $(\varepsilon)$ and the indirect utility is assumed to be a function of the choice attributes $Z$ with parameters $\beta$ and SED variables (Agimass and Mekonnen, 2011). According to Birol et al. (2005), the probability of choosing alternative $i$ in each of the choice set will have the following form:

$$
P_{\text {in }}=\exp \left(Z_{\text {in }}\left(\beta+h_{n}\right)\right) / \sum \exp \left(Z_{j n}\left(\beta+h_{n}\right)\right)
$$

2.1.2 Lancasterian theory of value. The Lancasterian theory has broken away from the traditional theory of consumer behavior that goods are the direct objects of utility and focused on the properties of the goods from which utility is derived. According to 
Lancaster (1966), the good does not give utility to the consumer, it possesses characteristics and these characteristics give rise to utility; good or service will possess more than one characteristic and these characteristics will be shared by more than one good or service. Goods in combination may possess characteristics different from those about the goods or services separately.

Assumed that an individual good or a collection of goods as a consumption activity and associate a scalar with it. It is also assumed that the relationship between the level of activity $K$ and $y_{k}$ the goods consumed in that activity to be linear and objective, so that, if $x_{j}$ is the $j$ th commodity

$$
x_{j}=\sum_{k} a_{j k} y_{k}
$$

with activity vector $x=A y$. Since the relationships are assumed to be objective, the equations are assumed to hold for all individuals, the coefficients $a_{j k}$ being determined by the intrinsic properties of the goods themselves. It is also assumed that each consumption activity produces a fixed vector of characteristics and that relationship is again linear, so that, if $z_{i}$ is the amount of the $i$ th characteristic

$$
z_{i}=\sum_{k} b_{i k} y_{k}
$$

with activity vector like $z=B y$. Again, it is assumed that the coefficients $b_{i k}$ are objectively determined for some arbitrary choice of the units of $z_{i}$. It is assumed that the individual possesses an ordinal utility function on characteristics $U_{z}$ and will choose a situation which maximizes $U_{z} . U_{z}$ is provisionally assumed to possess the ordinary convexity properties of a standard utility function. The chief purpose of making the assumption of linearity is to simplify problem. A viable model could certainly be produced under the more general set of relationships.

$$
F_{k}(z, x)=0 ; k=1 \ldots m
$$

In this model, the relationship between the collections of characteristics available to the consumer-the vectors $z$-which are the direct ingredients of his preferences and his welfare and the collections of goods available to him-the vector $x$-which represent his relationship with the rest of the economy, is not direct and one-to-one, as in the traditional model, but indirectly, through the activity vector $y$ (Lancaster, 1966).

2.1.3 Compensating surplus (CS). The study focused on purely discrete choice which implies that in some cases welfare measures have to be interpreted with ecosystem services. In the case of an experiment of ecosystem service of Sundarbans mangrove, the welfare measures are per person, depending on what has been defined in the survey. Let us consider the following utility function:

$$
U=h(A)+\gamma(Q, z) z+\varepsilon
$$

where the function $h(A)$ captures the effect of the different attributes on utility, $Q$ is a vector of personal characteristics and $z$ is a composite bundle. This characteristic of the traditional demand theory is very relevant to the marginal utility of income as it may also be affected by the personal characteristics of the individual like the level of income. For more simplification, let us start with the common case of constant marginal utility of income and independence of personal characteristics. Under this circumstance, the ordinary and compensated demand functions coincide (Alpizar et al., 2001). Given this functional form and the assumption of week complementary, it is possible to write the conditional indirect utility function for the 
FER

2,1

purely discrete choice as:

$$
U_{i}\left(A_{i}, P_{i}, y, \varepsilon\right)=h_{i}\left(A_{i}\right)+\bar{\gamma}\left(y-P_{i} c_{i}\right)+\varepsilon
$$

In addition, it is possible to write the probability that alternative $j$ is preferred as:

$$
\begin{aligned}
P\{i\} & =P\left\{h_{i}\left(A_{i}\right)+\bar{\gamma}\left(y-p_{i} c_{i}\right)+\varepsilon_{i}>h_{j}\left(A_{j}\right)+\bar{\gamma}\left(y-p_{j} c_{j}\right)+\varepsilon_{j} ; \forall j \neq i\right\} \\
& \left.=P\left\{h_{i}\left(A_{i}\right)+\bar{\gamma} p_{i} c_{i}+\varepsilon_{i}>h_{j}\left(A_{j}\right)+\bar{\gamma} p_{j} c_{j}\right)+\varepsilon_{j} ; \forall j \neq i\right\}
\end{aligned}
$$

Equation (15) indicates that income does not affect the probability of choosing a certain alternative under the current assumptions and hence the welfare measures will have no income effects (Alpizar et al., 2001). Thus, it is possible to express the unconditional indirect utility function as:

$$
U(A, p, y, s)=\bar{\gamma} y+\max \left[h_{1}\left(A_{1}\right)-p_{1} c_{1}+\varepsilon_{1}, \ldots, h_{N}\left(A_{N}\right)-p_{N} c_{N}+\varepsilon_{N}\right]
$$

The compensating surplus (Cs) is obtained by solving the equality: $V\left(A^{0}, P^{0}, y\right)=V\left(A^{1}\right.$, $p^{1}-C S$ ). Using the functional form in equation (16), we have:

$$
\begin{aligned}
\bar{\gamma} y & +\max \left[h_{1}\left(A_{1}^{0}\right)-p_{1}^{0} c_{1}+\varepsilon_{1}, \ldots, h_{N}\left(A_{N}^{o}\right)-p_{N}^{0} c_{N}+\varepsilon_{N}\right] \\
& =\bar{\gamma}(y-C S)+\max \left[h_{1}\left(A_{1}^{1}\right)-p_{1}^{1} c_{1}+\varepsilon_{1}, \ldots, h_{n}\left(A_{N}^{1}\right)-p_{N}^{1} c_{N}+\varepsilon_{N}\right]
\end{aligned}
$$

After simplification, it is possible to solve for $\mathrm{CV}$ and this results will take the following form:

$$
\mathrm{CS}=\frac{1}{\bar{\gamma}}\left[\begin{array}{l}
\max \left\{h_{1}\left(A_{1}^{1}\right)-p_{1}^{1} c_{1}+\varepsilon_{1}, \ldots, h_{n}\left(A_{N}^{1}\right)-p_{N}^{1} c_{N}+\varepsilon_{N}\right\}- \\
\max \left\{h_{1}\left(A_{1}^{0}\right)-p_{1}^{0} c_{1}+\varepsilon_{1}, \ldots, h_{N}\left(A_{N}^{o}\right)-p_{N}^{0} c_{N}+\varepsilon_{N}\right\}
\end{array}\right]
$$

According to Hanemann (1999), if the error terms are extreme value distributed, the expected CS for a change in attributes will be the following form:

$$
E(\mathrm{CS})=\frac{1}{\mu \bar{\gamma}}\left\{\ln \sum_{i \in S} \exp \left(\mu V_{i 1}\right)-\ln \sum_{i \in S} \exp \left(\mu V_{i 0}\right)\right\}
$$

where $\mu V_{i 0}$ and $\mu V_{i 1}$ represent the estimated indirect utility before and after the change of $\mu \bar{\gamma}$ is the confounded estimate of the scale parameter and the marginal utility of money and $S$ is the choice set. This measure is independent of scale and, in general, the scale parameter is set to equal one. When we consider a linear utility function and only change of one attribute, the CS for a discrete choice is given as:

$$
C S=\frac{1}{\gamma} \ln \left\{\frac{e^{V_{11}}}{e^{V_{10}}}\right\}=\frac{1}{\gamma}\left(V^{1}-V^{0}\right)=\frac{\beta_{k}}{\gamma}\left(A_{k}^{1}-A_{k}^{0}\right)
$$

2.1.4 Willingness-to-pay (WTP). The common objective of the conjoint analysis is the derivation of measures designed to determine the amount of money where participants are willing to forfeit to obtain benefits from the undertaking of some specific actions such as capture fisheries, fuel energy, storm protection, habitat for fish breeding and nursery grounds (Hensher et al, 2010). In a simple linear regression model, WTP is calculated as the ratio of two parameter estimates, holding all else constant (Iqbal, 2017). Provided at least one attribute or variable is counted in monetary units, the ratio of two parameters will able to generate a financial indicator of WTP. Value of ecosystem service (VES) of Sundarbans mangrove forest 
is defined as the amount of money villagers are willing to pay for ecosystem services in a year (365 days), ceteris paribus. More specifically, such a measure is used in measuring the pricing of conservation of ecosystem services. Mathematically it can be written as:

$$
\mathrm{VES}=-\frac{\beta_{i}}{\gamma} \times 365=-\left(\frac{\beta_{\text {ecosystem_service }}}{\beta_{\text {payment }}}\right) \times 365
$$

\section{Valuing ecosystem services of Sundarbans}

This study has multiplied the VES measured by 365 days or a year to give a measure of WTP in local currency Bangladeshi Taka. In calculating a measure of WTP, it is essential that both attributes and variables to be used in the calculation are found to be statistically significant, otherwise, no meaningful WTP measure can be established. WTP measures are also significant to environmental, ecological and resource economics studies in which a not uncommon objective is the valuation of non-monetary attributes such as air quality and water quality (Hensher et al., 2010).

\section{Methodology and research plan}

\subsection{Present study}

The study is based in Sundarbans mangrove forest located in the southwest coastal region in Bangladesh. The area of this forest is bounded by the Ganges River in the North, tributaries from the Meghna River in the East, an international boundary in the West, and the Bay of Bengal in the South. Sundarbans ecosystem formed the backbone of rural living and livelihoods because of its numerous contributions to agriculture, fishing, and aquaculture. Villagers of peripheral 76 villages to Sundarbans are dependent on the collection of natural tiger shrimp post larvae broodstock and seed for shrimp farming, capture fishery, wood, building material, golpata (Nypa-fructicans) and mangrove palm collection, honey collection, and snail, crab and oyster collection for their livelihood (Ekka and Pandit, 2012; Ahmed et al., 2009). Apart from its natural resource and ecological importance, Sundarbans ecosystems also provides direct and indirect income and employment opportunities to 1.7 million people across the border villages of Sundarbans (Inskip et al., 2013). The kind, nature, and the number of income-generating activities available to villagers become increasingly restricted as village proximity to Sundarbans (Murtaza, 2001). However, depending on livelihoods on this forest are threatened due to frequent occurrence of natural extreme events like the high level of risks in the form of cyclonic storms, tidal creek erosion, embankment failures, salinity intrusion, waterlogging and unexpected coastal flooding.

\subsection{Study specification}

The Economics of Ecosystems and Biodiversity (TEEB) (2010) guided ecosystem service approach was followed to assess and value of ecosystem of Sundarbans mangrove. TEEB approach makes a stronger relationship between ecosystem services and human well-being and economic benefits. According to Rahman et al. (2018), the ecosystem services of Sundarbans should be identified and assessed through (1) analyzing mangrove in terms of ecosystems (socio-economic characteristics, natural hazards, use of land and resources, and drives of changes) and relevant community people who get benefits from Sundarbans; (2) quantify those ecosystem services responsible for making sustainability and benefits for local people; and (3) figure out the values of mangrove ecosystem services subject to ecological, social-cultural and economic indicators.

Instruments of both the quantitative and qualitative research approaches were used to collect data for analysis. Data were collected through focus group discussion (FGD) and household surveys. 
FER

2,1

124

FGDs organized with 10-12 people in each of the three villages adjacent to Sundarbans. The participants were selected in a non-random fashion. The objective set to each group was to identify the attributes and their levels, understand household characteristics, and livelihood activities, and importance of the Sundarbans mangrove ecosystem. To fulfill the objective, concern facilitators helped each group to identify the types of attributes of ecosystem services. After identification of the attributes, the groups were requested to separate into a smaller section of three or four persons and determine the levels of attributes. After that exercise, four attributes and their associated levels were then chosen. The proposed attributes and their levels include storm protection, erosion control, habitat for fish breeding, and payment. The first two are known as regulating services and the third is known as supporting service (Rahman et al., 2018). All regulating and supporting services were jointly revealed by the level of interests such as highly interested, interested, and slightly interested. As these services have non-market value, the market scenario was specified within which to elicit FGD driven WTPs such as Tk. 1,000, Tk. 1,500, and Tk. 2,000 for these ecosystem services related attributes. The selected attributes and their associated levels are shown in Table 1 . The values presented in local currency (BDT Bangladeshi Taka), equivalent to US\$ using a conversion rate of BDT 81 to US\$ 1 corresponding to May 2015.

Experimental design helps to create the choice sets efficiently. Orthogonal matrix was used as the principal part of an efficient design. This study used four attributes, as stated in Table 1. A full factorial design includes all possible combinations of attributes and levels, results in 81 possible combinations $\left(3^{4}=3 \times 3 \times 3 \times 3=81\right)$ using an orthogonal design by SPSS econometric software. According to orthogonal design principle, by using fractional design, this study reduced it randomly to 16 for four versions of choice card and each version contains three alternatives (options) including the status quo with replacement procedure. Each respondent answered twice the choice cards. A sample of a choice set provided to respondents is shown in Table 2.

The household surveys were conducted by face to face interviews based on a semistructured questionnaire and a pack of cards in the seven villages from 22 December 2015 to 27 February 2016. Stratified random sampling method was applied to the whole population of targeted seven villages located within $1.5 \mathrm{~km}$ of Sundarbans and divided

Table 1.

Attributes and their associated levels

\begin{tabular}{lllll}
\hline Name of the attributes & Current level & \multicolumn{3}{c}{ Level of payment and interest } \\
\hline Yearly payment for ecosystems & No measure & Tk. 1,000 & Tk. 1,500 & Tk. 2,000 \\
Storm protection & No measure & Highly interested & Interested & Slightly interested \\
Erosion control & No measure & Highly interested & Interested & Slightly interested \\
Habitat for fish breading & No measure & Highly interested & Interested & Slightly interested \\
Source(s): Author's calculation using data from FGD, 2015 & & \\
\hline
\end{tabular}

\begin{tabular}{llll}
\hline Name of the attributes & Option A & Option B & No change (Status quo) \\
\hline Payment for ecosystem & Tk. 1,500 & Tk. 1,000 & No change \\
Storm protection & Highly interested & Slightly interested & No change \\
Erosion control & Interested & Highly interested & No change \\
Habitat for fish breading & Highly interested & Interested & No change \\
Your choice (tike one only) & A & B & I would not want either A or B
\end{tabular}

Source(s): Author's calculation using data from FGD, 2015
Table 2. An example of choice task 
them into few homogenous sub-groups (fishermen, traders, and farmers) based on their occupational status and then taken a simple random sample in each sub-group. The survey involved 221 respondents selected from the seven villages (Jorshing Patakhali and Jaigirmahal in Koyra Sub-District, Joymony Ghol, Burburia, Joymony Sankirchar and Sonailtola in Mongla Sub-District, Kultali in Shyamnager Sub-District), in which 195 respondents aged 18 and above were agreed to participate in the survey process. In the whole survey process, respondents were briefed about the proposed regulating and supporting services associate with the Sundarbans ecosystem, how their livelihood relies on these services, and how payment of ecosystem services ensures the sustainability of Sundarbans ecosystems and their livelihood.

As much as possible, the selection of respondents is random, but there is a possibility to occur sampling error. The following procedures were taken in reducing the bias of the conjoint analysis. All survey interviews were conducted by the trained data collectors. All respondents have briefed the importance of the ecosystem of Sundarbans mangrove forests for better livelihood options. The interview of respondents was taken care of for a long time. The data collectors do not indulge in any personal and irrelevant gossiping to avoid anchoring or influencing the answers of the respondents.

The questionnaire for household surveys consists of a few sections. The first section covered the socio-economic background of households and their livelihood patterns. The second section highlighted the perceptions of ecosystem services provided by Sundarbans and their importance to villagers. The third section and final section included choice chard experiment eliciting respondents' WTP for improved ecosystem services of Sundarbans that have non-market value.

\subsection{Nature of collected data and model specification}

Collected data have many zero responses that revealed the respondent's unwillingness to pay for the ecosystem services of Sundarbans mangrove forest. Random parameter logit or basic model is successfully applied for zero responses when both the decision in ecosystem services and payment for ecosystem services are taken jointly (Jones, 2000). In the first step of estimation, a random parameter logit model was run for participation decision in ecosystem services where 1 indicates positive perception for proposed ecosystem services and 0 indicates otherwise is regressed on explanatory variables (Jones, 2000). Whereas, in the second step of estimation, a multinomial logit model or extended model was run which includes all ecosystem services related attributes and respondents' SED characteristics with alternative specific constant (ASC).

Equation (22) presents respondents' level of interest on proposed ecosystem services and their associate level of payments and known as functional form basic or random parameter logit model. Equation (23) is the functional and extended form of the basic model where SED characteristics are additionally incorporated and known as extended or multinomial logit model.

$$
\begin{gathered}
Y_{1}=f\left(\text { Attribute }_{i}\right) \\
Y_{2}=f\left(\text { Attribute }_{i}, \mathrm{SED}_{i}\right)
\end{gathered}
$$

where $Y_{1}$ is the ecosystem service of Sundarbans mangrove forest dummy, $Y_{2}$ is also the ecosystem service of Sundarbans forest dummy, $f$ is indicates the functional relationship of explanatory and outcome variables. Attribute covers yearly payment for ecosystem services, storm protection, erosion control, and habitat for fish breeding. SED is socio-economicdemographic characteristics (e.g. age, monthly income, gender, family size, occupational status and education). 
FER

2,1

126

\section{Survey findings}

\subsection{Descriptive statistics of the variables in the model}

Based on the collected data obtained from field surveys in seven villages adjacent to Sundarbans mangrove forest, basic descriptive statistics of major variables are calculated (see Table 3 for more details).

A total of 195 villagers from seven villages participated in the survey where $91 \%$ were male and $9 \%$ were female. More than $87 \%$ of villagers were argued that ecosystem services of Sundarbans mangrove can play important role to improve their livelihood conditions. About $71 \%$ of respondents were interested to pay for ecosystem services. More than $47 \%$ of respondents were involved in agricultural activities, $32 \%$ of respondents were fishermen, and the rest of $21 \%$ were traders. Though all the villagers were appreciated the improved ecosystem services, $21 \%$ of respondents were not interested to pay for the proposed ecosystem services due to low income, and effective utilization of collected funds. They argued that the government should fund the proper ecosystem services. About $83 \%$ of respondents strongly agreed that ecosystem services of Sundarbans mangrove forest have degraded. Table 3 outlines the summary statistics. The average age of the respondents is 32 years and they played a significant role in decision making. On average, the survey villagers have monthly income $4,000 \mathrm{Tk}$. About $27.8 \%$ of the respondents possessed secondary school certificate (SSC) examination and higher secondary certificate (HSC) examination, $33.6 \%$ of respondents had completed primary education and the rest of $38.6 \%$ of respondents were illiterate. The mean residential distance from Sundarbans was $0.63 \mathrm{~km}$. The range of maximum and minimum payment for ecosystem services was 2,000 $\mathrm{Tk}$ and 1,000 Tk respectively. The majority of the villagers have five family members.

\subsection{Results of regression models}

Random parameter logit (RPL) or basic and multinomial logit (MNL) or extended models are applied to quantify the ecosystem services and measure WTP and welfare effects through CS. Results for all 195 respondents from RPL and MNL models are shown in Table 4.

As indicated in Table 4, the estimated results in the RPL model make the guarantee that payment for ecosystem services, habitat for fish breeding, storm protection and erosion control are the contributors to ecosystem services of Sundarbans mangrove forest. Payment for ecosystem services in the RPL model to have negative and significant effects on the probability of respondents accepting the payment for ecosystem services. The negative sign of payment satisfies the law of demand. Similarly, the estimated results in the MNL model also make the guarantee that SED characteristics such as age, income, family size, education and occupational status along with proposed attributes are found to be important contributors to WTP. But it is not possible to say about the relationship between gender and ecosystem service. During the survey time, a smaller number of female respondents took part in the survey and that may cause insignificancy of gender. Generally, education, stable income, small family size and occupation are more sensitive to ecosystem services of

Table 3.

Brief descriptive statistics of the variables

\begin{tabular}{lccrr}
\hline Variables & Maximum & Minimum & Mean & Standard deviation \\
\hline Age (years) & 71 & 18 & 32.38 & 13.13 \\
Monthly income (Tk.) & 150,000 & 0 & 4000.09 & 23631.94 \\
Education (years of schooling) & 12 & 0 & 5.52 & 3.02 \\
Family size (Persons of family) & 12 & 4 & 5.14 & 1.78 \\
Residential distance from Sundarbans (km) & 1.5 & 0.37 & 0.63 & 0.34 \\
Source(s): Authors' calculation based on survey data, 2016 & & & \\
\end{tabular}




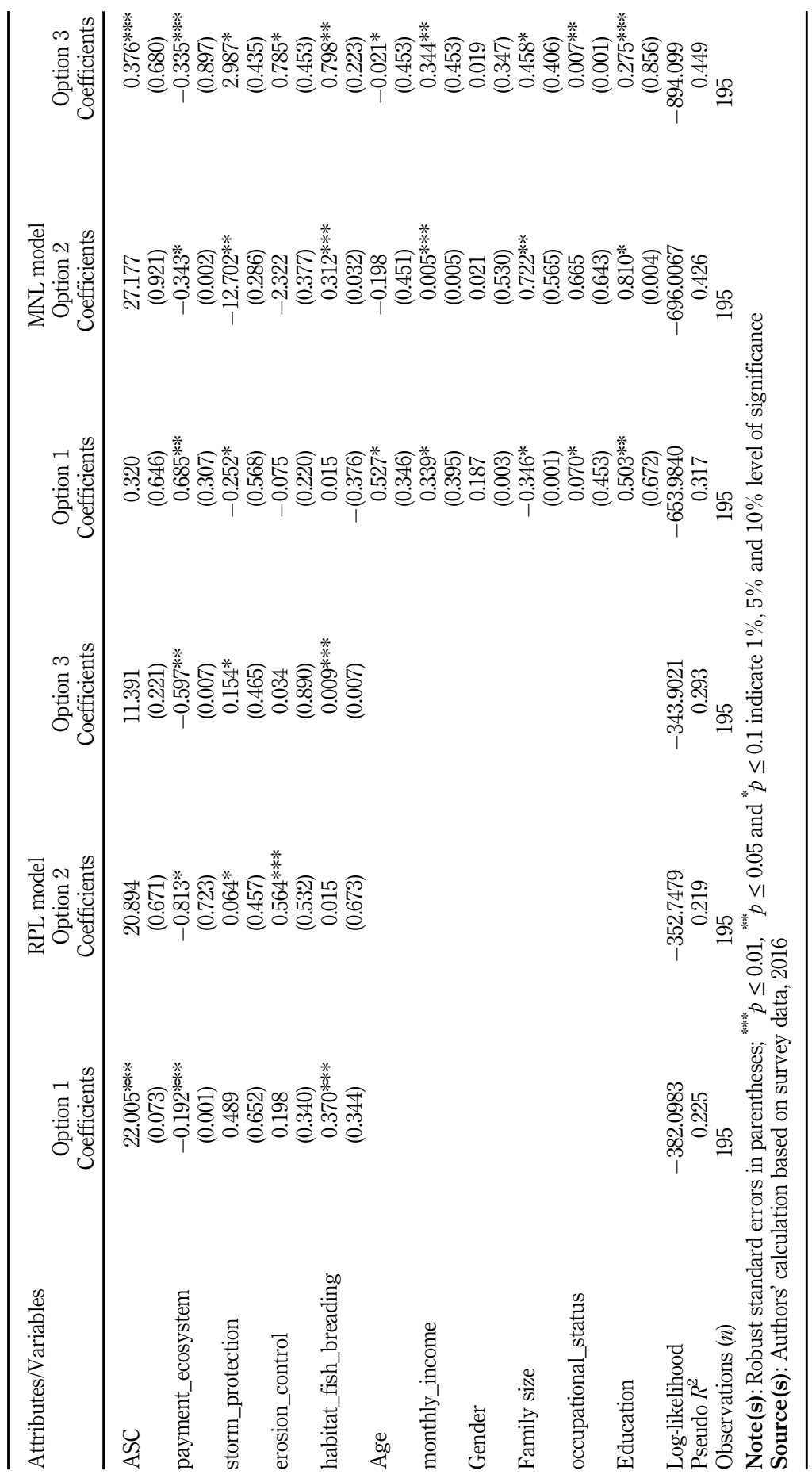

Table 4. Regression results of the survey 
FER

2,1

128

environment, ecology, and biodiversity (Sandifer et al., 2015). There are some similar results obtained in the literature in terms of education (years of schooling) of the respondents. For instance, Ekka and Pandit (2012) found that education 1\% increase in education will lead to increase in ecosystem services of Sundarbans mangrove. Education makes people more conscious of the forest ecosystem. Households' income has also positive impacts on the ecosystem of the mangrove forest. A similar result is founded by Salam et al. (2000). They argued that income stability of household helps to develop a well-planned ecosystem and it further motivates household to provide small amount of money like corporate social responsibility (CSR) for proper management of the Sundarbans mangrove forest ecosystem. Occupation is another leading influential factor that promotes ecosystem services. Therefore, it is a potential contributor to mangrove forest ecosystem. The coefficient of this variable in the study is significant at 5\% probability level which implies that an increase in the occupation will lead to developed ecosystem services at $0.7 \%$. A similar result is also found in the study of Ogeh et al. (2016). In their study, it is found that occupation is a significant factor that influences mangrove forest ecosystem services.

\subsection{Result of willingness-to-pay (WTP)}

WTP expresses the amount of money with respect to respondent's willingness to pay for better ecosystem services. The differences in the value of WTP may be explained by the respondents' characteristics and attitudes towards the proposed ecosystem services. WTP for attributes for ecosystem services is estimated using equation (21). The estimated WTP for three options in the RPL model is outlined in Table 5.

Estimated results from WTP revealed that villagers could ready to pay more Tk. 1.940 in daily and Tk. 703 in yearly for ecosystem service in option 1. It will be Tk. 0.77 and Tk. 0.16 in daily for ecosystem services in options 2 and 3 respectively and Tk. 281 and Tk. 59 in yearly for ecosystem services. The upper payment in option 1 indicates that villagers prefer more ecosystem service for better livelihood. The lower payments do not necessarily imply low demand for the ecosystem as the findings from WTP illustrate potential demand for ecosystem services.

\subsection{Result of compensating surplus}

The main purpose of compensating surplus is to be estimated the welfare effects of change in the attributes (Alpizar et al., 2001). To analysis this situation, this study assumed a simple

Table 5.

Estimation of WTP for ecosystem services of Sundarbans mangrove forest

\begin{tabular}{lccr}
\hline Options & Estimated value & Standard error & $P$-value \\
\hline Option 1 & $1.94^{* * * *} \times 365=703$ & 0.879 & 0.000 \\
Option 2 & $0.77^{* * *} \times 365=281$ & 0.432 & 0.000 \\
Option 3 & $0.16^{* *} \times 365=59$ & 0.320 & 0.021
\end{tabular}

Note(s): ${ }^{* * * *} p \leq 0.01$ and ${ }^{* * *} p \leq 0.05$ indicate $1 \%$ and $5 \%$ levels of significance

Source(s): Authors' calculation based on survey data, 2016

Alternative improvement scenario

Lower ecosystem services (Option 1)

Table 6.

Estimation of welfare effects
Moderate ecosystem services (Option 2)

Higher ecosystem services (Option 3)

Source(s): Authors' calculation based on survey data, 2016
Economic benefits from WTP for ecosystem services

Tk. $2.082 \times 365=$ Tk. 760

Tk. $0.378 \times 365=$ Tk. 138

Tk. $0.947 \times 365=$ Tk. 346 
utility function by imposing a constant marginal utility of income. But it depends upon purely discrete choices under three different options for ecosystem services of Sundarbans mangrove forest. Economic welfare management involves an investigation into the difference between the utilities of the individual that could be achieved under the status quo and alternative scenarios (Bennett and Blamey, 2001; Agimass and Mekonnen, 2011). Using equation (20), the estimated result of welfare effects is shown in Table 6.

Villagers will get more yearly surplus from the lower ecosystem services (option 1) and it is estimated at Tk. 760. After that, they will get more yearly surplus from the higher ecosystem services (option 3) and the moderate ecosystem services (option 2) where they get Tk. 346 and Tk. 138 respectively.

\section{Conclusions}

The mangrove forest ecosystem is typical of many environmental issues where non-use value may be highly significant. It draws greater attention with respect to villagers' livelihood options and disaster risk reduction. The lack of recognition of non-use and other components of the value of market systems and other decisions may hamper the ecosystem services of Sundarban. Based on the survey data, this study effectively highlights villagers' responsibility for the mangrove forest ecosystem. Findings from the study expressed that a large number of surveyed respondents were highly concerned about the ecosystem services of Sundarbans. They had deep expressed their interest to pay for further improvement of ecosystem services through storm protection, erosion control, and habitat for fish breeding. SED characteristics such as age, monthly income, family size, occupational status, and years of schooling are found to be important contributors to WTP. Hence, any policy aiming to undertake ecosystem services of Sundarbans mangrove is needed to take into consideration these factors for its effective implementation. The study findings can serve as policy inputs not only for Sundarbans, but also pave the way for undertaking similar projects like biodiversity control management to mitigate extinction of species in red alert.

The conjoint analysis is highly controversial due to its complicacy generated from a possible conflict of interest within the economics community (Kolstad, 2016). Generally, the values elicited in the conjoint analysis do not base on real resource decisions. Without real resources at stake, the response to WTP is insignificance, meaningless, and aimless. Hypothetical bias is the potential outcome of conjoint analysis. Respondents do not make choices subject to the budget constraint when overestimation or hypothetical bias of WTP appears (Whittington et al., 2010). The conjoint analysis may also be affected by enumerator bias, which that is respondents eliciting positive WTP to satisfy the interviewer (Chopra and Das, 2019). Another problem with conjoint analysis is called embedding. A typical problem for the conjoint analysis survey is to determine the value of a certain natural resource like ecosystem of the particular forest. There are usually substitute ecosystems outside of the domain of the survey and there appear to be inconsistencies in how respondents value ecosystem services of individual forest versus a group of forests (Kolstad, 2016). The study is based on a small sample size that leads to make few variables insignificance in econometric models. As a consequence, it is not possible to get a clear direction of WTP for ecosystem services of Sundarbans mangrove.

\section{References}

Agimass, F. and Mekonnen, A. (2011), "Low-income fishermen's willingness-to-pay for fisheries and watershed management: an application of choice experiment to Lake Tana, Ethiopia", Ecological Economics, Vol. 71, pp. 162-170. 
FER

2,1

Ahmed, I.U., Greenwood, C.J., Barlow, A.C.D., Islam, M.A., Hussain, A.N.M., Khan, M.M.H. and Smith, J.L.D. (2009), Bangladesh Tiger Plan 2009-2017, Bangladesh Forest Department, Ministry of Environment and Forests, Government of the People's Republic of Bangladesh, Dhaka.

Alpizar, F., Carlsson, F. and Martinsson, P. (2001), "Using choice experiments for non-market valuation", Working Paper in Economics No. 52, Gothenburg University, Sweden.

Amin, M.R. (2018), "Sustainable tourism development in Sundarbans, Bangladesh (a world heritage site): issues and actions", Journal of Business Studies, Vol. 39 No. 2, pp. 31-52.

Austin, D.E., Baro, M., Batterbury, S., Bouard, S., Carrasco, A., Gezon, L.L., Kowasch, M., Liebow, E., Meltzhoff, S.K., Niang, N. and Nijbroek, R. (2020), Terrestrial Transformations: A Political Ecology Approach to Society and Nature, Lexington Books, Washington, DC.

Banerjee, A.V. and Duflo, E. (2019), Good Economics for Hard Times, Juggernaut Books, New Delhi.

Ben-Akiva, M.E. and Lerman, S. (1985), Discrete Choice Analysis: Theory and Application Travel Demand, MIT Press, Cambridge.

Bennett, J. and Blamey, R. (2001), The Choice Modeling Approach to Environmental Valuation, Edward Elgar Publishing, Cheltenham.

Bergmann, A., Hanley, N. and Wright, R. (2006), "Valuing the attributes of renewable energy investment”, Energy Policy, Vol. 34, pp. 1004-1014.

Birol, E., Karousakis, K. and Koundouri, P. (2005), "Using a choice experiment to estimates the nonuse values of wetlands: the case of Cheimaditida wetland in Greece", Environmental Economy and Policy Research Discussion Paper Series, University of Cambridge: Department of Land Economy.

Cameron, A.C. and Trivedi, P.K. (2005), Microeconomics: Methods and Application, Cambridge University Press, New York.

Chopra, V. and Das, S. (2019), "Estimating willingness to pay for wasterwater treatment in New Delhi: contingent valuation approach”, Ecology, Economy and Society-the INSEE Journal, Vol. 2 No. 2, pp. 75-108.

Daily, G.C., Alexander, S., Ehrlich, P.R., Goulder, L., Lubchenco, J., Matson, P.A., Mooney, H.A., Postel, S., Schneider, S.H., Tilman, D. and Woodwell, G.M. (1997), "Ecosystem service: benefits supplied to human societies by natural ecosystems", Ecology, Vol. 2, pp. 1-15.

Ekka, A. and Pandit, A. (2012), "Willingness to pay for restoration of natural ecosystem: a study of Sundarban mangroves by contingent valuation approach", Indian Journal of Agricultural Economics, Vol. 67 No. 3, pp. 232-333.

Ghosh, A., Schmidt, S., Fickert, T. and Nüsser, M. (2015), "The Indian Sundarban mangrove forests: history, utilization, conservation strategies and local perception", Diversity, Vol. 7 No. 2, pp. 149-169.

Giri, C., Zhu, Z., Tieszen, L.L., Singh, A., Gillette, S. and Kelmelis, J.A. (2008), "Mangrove forest distribution and dynamics (1975-2005) of the Tsunami affected region of Asia", Journal of Biogeography, Vol. 35 No. 3, pp. 519-522.

Gunawardena, M. and Rowan, J.S. (2005), "Economic valuation of a mangrove ecosystem threatened by shrimp aquaculture in Sri Lanka”, Environmental Management, Vol. 36 No. 4, pp. 535-550.

Hanemann, M. (1999) "Welfare analysis with discrete choice models", in Herriges, J. and Kling, C. (Eds), Valuing Recreational and the Environment, Edward Elgar, Cheltenham.

Hanley, N., Bergmann, A. and Wright, R. (2001), Valuing the Environmental and Employment Impacts of Renewable Energy Investment in Scotland. Scotecon, Stirling.

Henderson, J.M. and Quandt, R.E. (1980), Microeconomic Theory: A Mathematical Approach, McGrowHill Book Company, Singapore.

Hensher, D.A., Rose, J.M. and Green, W.H. (2010), Applied Choice Analysis: A Primier, Cambridge University Press, New York. 
Hussain, S.A. and Badola, R. (2010), "Valuing mangrove benefits: contribution of mangrove forests to local livelihoods in Bhitarkanika conservation area, east coast of India”, Wetlands Ecology and Management, Vol. 18, pp. 321-331.

Inskip, C., Ridout, M., Fahad, Z., Tully, R., Barlow, A., Barlow, C.G., Islam, M.A., Roberts, T. and MacMillan, D. (2013), "Human-tiger conflict in context: risks to lives and livelihoods in the Bangladesh Sundarbans”, Human Ecology, Vol. 41 No. 2, pp. 169-186.

Iqbal, M.H. (2017), "Choice modeling and its application to Sundarbans mangrove forest preservation", in Nawn, N. and Elamon, J. (Eds), Sustainability, Institutions, Incentives: Voices, Policies and Commitments, Conference Proceedings, Indian Society for Ecological Economics (INSEE), Delhi, India, pp. 13-38.

Iqbal, M.H. (2020), "Valuing ecosystem services of Sundarbans mangrove forest", Global Ecology and Conservation, Vol. 24 e01273.

Islam, S.D.U. and Bhuiyan, M.A.H. (2018), "Sundarbans mangrove forest of Bangladesh: causes of degradation and sustainable management options", Environmental Sustainability, Vol. 1 No. 2, pp. 113-131.

Islam, S.N. (2014), "An analysis of the damages of Chakoria Sundarban mangrove wetlands and consequences on community livelihoods in south east coast of Bangladesh", International Journal of Environment and Sustainable Development, Vol. 13 No. 2, pp. 153-171.

Jones, A.M. (2000), "Health economertics", in Culyer, A.J. and Newhouse, J.P. (Eds), Handbook of Health Economics, Vol. 1, pp. 265-344.

Kolstad, C.D. (2016), Intermediate Environmental Economics, Oxford University Press, New Delhi.

Lancaster, K. (1966), “A new approach to consumer theory”, Journal of Political Economy, Vol. 74 No. 2, pp. 132-157.

Louviere, J.J., Hensher, D. and Swait, J. (2000), Stated Choice Methods: Analysis and Application, Cambridge University Press, New York.

Manski, C. (1977), "The structure of random utility models: theory and decision", Theory and Decision, Vol. 8 No. 3, pp. 229-254.

McFadden, D. (1974), “Conditional logit analysis of qualitative choice behavior”, in Zarembka, P. (Ed.), Frontiers in Econometrics, Academic Press, New York.

Mukherjee, N., Sutherland, W.J., Dicks, L., Huge, J., Koedam, N. and Dahdouh-Guebas, F. (2014), "Ecosystem service valuations of mangrove ecosystems to inform decision making and future valuation exercises", PloS One, Vol. 9 No. 9, e107706.

Murtaza, M.G. (2001), Socio-Economic Baseline Study of the Impact Zone of the Sundarbans. Sundarbans Biodiversity Conservation Project Report, Forest Department, Government of Bangladesh, Khulna.

Muthukrishnan, S. (2015), Economics of Environment, PHI Learning Private Limited, Delhi.

Ogeh, K.T., Jimoh, S.O. and Ajewole, O.I. (2016), "Willingness to pay for environmental service functions of mangrove forest in Uzere, Delta State, Nigeria", Journal of Resource Development and Management, Vol. 16, pp. 1-7.

Protect Planet (2018), Sundarbans West Wildlife Sanctuary, available at: https://www.protectplanet. net/sundarbans-west-wildlife-sanctuary.

Rahman, M.M. and Begum, S. (2011), "Land cover change analysis around the Sundarbans mangrove forest of Bangladesh using remote sensing and GIS application”, Journal of Science Foundation, Vol. 9 Nos $1 \& 2$, pp. 95-107.

Rahman, M.M., Jing, Y. and Irvine, K. (2018), “Assessing wetlands services for improved development decision-making: a case study of mangroves in coastal Bangladesh", Wetlands Ecology and Management, Vol. 26, pp. 563-580.

Salam, M.A., Lindsay, G.R. and Bevverridge, Mm.C. (2000), "Eco-tourismm to protect the reserve mangrove forest the Sundarbans and its flora and fauna", Anatolia, Vol. 11 No. 1, pp. 56-66. 
FER

2,1
Sandifer, P.A., Sutton-Grier, A.E. and Ward, B.P. (2015), "Exploring connections among nature, biodiversity, ecosystem services, and human health and well-being: opportunities to enhance health and biodiversity conservation", Ecosystem Services, Vol. 12, pp. 1-15.

Sen, H.S. and Ghorai, D. (2019), "The Sundarbans: a flight into the wilderness", in The Sundarbans: A Disaster-Prone Eco-Region, Springer, Cham.

Shameem, M.I.M., Momtaz, S. and Rauscher, R. (2014), "Vulnerability of rural livelihoods to multiple stressors: a case study from the southwest coastal region of Bangladesh", Ocean and Coastal Management, Vol. 102, pp. 79-87.

The Economics of Ecosystems and Biodiversity (2010), Mainstreaming the Economics of Nature: Asynthesis of the Approach, Conclusions and Recommendations of TEEB, Progress Press, Malta.

Uddin, M.S., van Steveninck, E.D.R., Stuip, M. and Shah, M.A.R. (2013a), "Economic valuation of provisioning and cultural services of a protected mangrove ecosystem: a case study on Sundarbans Reserve Forest, Bangladesh”, Ecosystem Services, Vol. 5, pp. 88-93.

Uddin, M.S., Shah, M.A.R., Khanom, S. and Nesha, M.K. (2013b), "Climate change impacts on the Sundarbans mangrove ecosystem services and dependent livelihoods in Bangladesh", Asian Journal of Conservation Biology, Vol. 2 No. 2, pp. 152-156.

UNESCO (2018), The Sundarbans, available at: http://whc.unesco.org/en/list/798.

Whittington, D.D.T., Lauria, A.M., Wright, K., Choe and Hughes, J.A. (2010), "Household demand for improved sanitation services in Kumasi, Ghana: a contingent valuation study", Water Resources Research, Vol. 29 No. 6, pp. 1539-1560.

\section{Corresponding author}

Md. Hafiz Iqbal can be contacted at: vaskoriqbal@gmail.com

For instructions on how to order reprints of this article, please visit our website:

www.emeraldgrouppublishing.com/licensing/reprints.htm

Or contact us for further details: permissions@emeraldinsight.com 